\title{
An Empirical Study on Green Investment and Economic Growth in China
}

\author{
Xuanjian Zhang ${ }^{1}$, Ya Gui ${ }^{\text {1* }}$ \\ ${ }^{1}$ School of Business, Chongqing Vocational College of Transportation, Chongqing, 402247, China;
}

\begin{abstract}
China's economy is changing from high-speed growth to high-quality development. Environmental governance investment is an important measure to promote high-quality economic development. According to the Environmental Kuznets curve, there is an inverted U-shaped relationship between environmental pollution and economic growth. And in the long run, the green investment in environmental governance will certainly promote economic growth; but in the short term, a large amount of money used to control pollution will inevitably have a negative impact on economic growth. Based on empirical analysis, this paper studies the relationship between environmental governance investment and economic growth in China. The conclusion shows that there is a positive correlation between environmental governance investment and economic growth in China at this stage, and based on this, some suggestions are put forward.
\end{abstract}

\section{Introduction}

Since the reform and opening up, China's economy has gained the world's attention. However, as a developing country, China's economic activities inevitably lead to resource depletion and environmental pollution. As a result of economic growth, it brings serious environmental problems, including the emission of waste gas, waste water and sulfur dioxide.

In order to achieve good economic development and progress, we need to constantly improve the relationship between environmental governance and economic growth, so as to drive economic development and progress, promote environmental governance to become normalized in China, and then drive economic development and stability, improve the relationship between environmental governance and economic growth, strengthen the government's intervention, and then drive economic growth.

On the one hand, people marvel at the rapid growth of China's economy; on the other hand, they also strongly demand that China can improve the environment to ensure sustainable economic development. Therefore, in recent years, China has invested a large amount of investment in environmental governance to alleviate the problem of environmental pollution.

Economists try to incorporate environmental factors into the system of national economic accounting, and try to measure a country's economic growth, at the same time, consider the consumption of resources and the destruction of ecological environment, so as to comprehensively reflect the changes of environment and economy. They proposed to adjust the existing GDP indicators with the depletion value of natural resources, the degradation cost of ecological environment and the restoration cost of natural resources and environmental resources, that is, to deduct the depletion value of natural resources, the degradation cost of ecological environment and the restoration cost of natural resources and ecological environment from the gross national product, which is green GDP.

But at present, green GDP does not operate in a large scale in practice. Under the background of green GDP accounting system not put into practice, what kind of impact will the investment in environmental governance have on GDP? Grossman and Krueger pointed out for the first time that the relationship between economic growth and pollution is an inverted U-shaped curve. The relationship between pollution and per capita income is "pollution increases with the increase of per capita GDP at low income level, and decreases with the growth of per capita GDP at high income level". ${ }^{1]}$ Therefore, according to the inverted U-shaped Environmental Kuznets curve, the green investment for environmental governance is also a U-shaped curve with inflection point. And in the long run, green investment will certainly promote economic growth; but in the short term, a large amount of money used to control pollution will inevitably have a negative impact on economic growth.

At the present stage of China, what kind of role does green investment play in environmental governance for economic growth? This paper makes an empirical

*Corresponding author:350517735@qq.com 
analysis of the data in recent years to study the impact of environmental governance investment on economic growth. This paper holds that the effect of the investment on economic growth should be negative at first, and then turn into promoting effect when the economy develops to a certain stage.

\section{Current situation of green investment in China}

Environmental governance investment is often referred to as green investment in academic circles, mainly including micro and macro perspectives. From the micro perspective, green investment, from the perspective of enterprises, should not only pay attention to the benefits, but also take into account the impact on the environment, society and economy, ${ }^{[2-3]}$ so it is also called "triple surplus" investment. From the macro perspective, green investment refers to the investment that can promote the growth of green GDP. ${ }^{[4]}$

In this paper, macro perspective data analysis of China's environmental governance issues. In recent years, China's emissions of waste gas, waste water and solid waste are on the rise in general, and the form is grim. Therefore, China invests a large amount of money every year to control the "three wastes".

Table 1. China's investment in the treatment of three wastes.

\begin{tabular}{ccccc}
\hline year & $\begin{array}{c}\text { Completed investment } \\
\text { of waste water } \\
\text { treatment project } \\
(10000 \text { yuan })\end{array}$ & $\begin{array}{c}\text { Completed investment } \\
\text { of waste gas treatment } \\
\text { project (10000 yuan) }\end{array}$ & $\begin{array}{c}\text { Completed investment } \\
\text { of solid waste treatment } \\
\text { project (10000 yuan) }\end{array}$ & Total (10000 yuan) \\
\hline 2004 & 106 & 143 & 23 & 272 \\
2005 & 134 & 213 & 27 & 374 \\
2006 & 151 & 233 & 18 & 402 \\
2007 & 196 & 275 & 18 & 489 \\
2008 & 195 & 266 & 20 & 481 \\
2009 & 149 & 232 & 22 & 403 \\
2010 & 130 & 188 & 14 & 332 \\
2011 & 158 & 212 & 31 & 401 \\
2012 & 140 & 258 & 25 & 423 \\
2013 & 125 & 641 & 14 & 780 \\
2014 & 115 & 789 & 15 & 919 \\
2015 & 118 & 522 & 16 & 656 \\
2016 & 108 & 561 & 47 & 716 \\
2017 & 76 & 446 & 13 & 535 \\
\hline
\end{tabular}

As shown in Table 1, China's investment in the treatment of three wastes has increased steadily in recent years: from 2.72 million yuan in 2004 to 5.35 million yuan in 2017, with 9.19 million yuan invested in 2014 at the most.Among them, the investment in controlling waste gases grew fastest: from 1.43 million yuan in 2004 to 4.46 million yuan in 2017 , and 7.89 million yuan was invested in 2014 at the most.

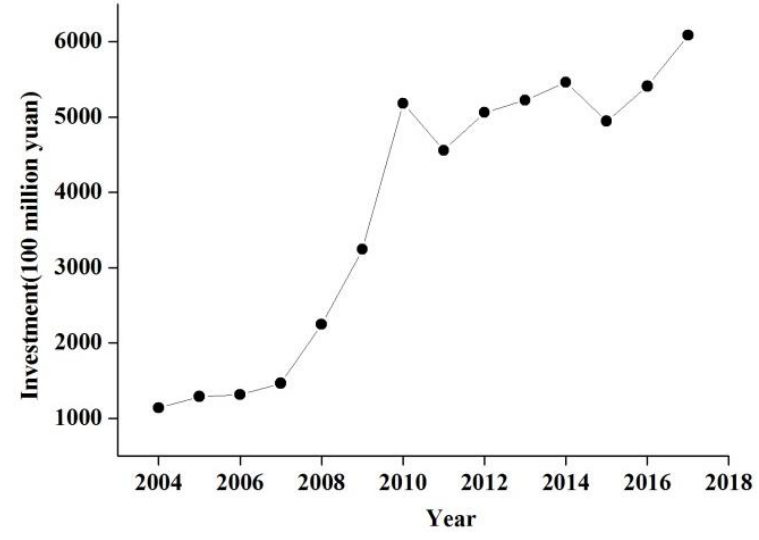

Fig 1. Investment in urban environmental infrastructure construction in China

Environmental infrastructure construction investment is also an important green investment. As shown in Fig 1, in recent years, China's urban environmental infrastructure construction investment has increased significantly: from 114.12 billion yuan in 2004 to 608.575 billion yuan in 2017 , with an average annual growth rate of $13.74 \%$.

It can be seen that China's investment in environmental governance has been increasing in recent years, which shows that China is paying more and more attention to the coordinated development of economy and environment while focusing on economic growth.

\section{Econometric analysis}

\subsection{Basic assumptions}

According to the existing research, this paper decomposes green investment into two indicators: total of three wastes treatment investment (f) and urban environmental infrastructure construction investment $(\mathrm{J})$. Economic growth is represented by GDP value (y). In this way, the following model is constructed by using the relevant settings of $\mathrm{CD}$ production function:

$$
\ln \mathrm{Y}=\mathrm{C}+\alpha \ln \mathrm{F}+\beta \ln \mathrm{J}+\mu
$$

This paper selects the annual data of China from 2004 to 2017 and adopts the stepwise regression method 
for analysis. In order to weaken heteroscedasticity, all data are logarithmic.

According to the relevant theory, this paper gives the theoretical expectation: the regression coefficients of $\mathrm{F}$ and $\mathrm{j}$ are positive, that is, the investment in the treatment of three wastes and the investment in urban environmental infrastructure construction can have a positive impact on economic growth.

\subsection{Regression analysis}

(1) According to the above data, regression analysis was made for $\ln \mathrm{Y}=\mathrm{C}+\alpha \ln \mathrm{F}+\mu$ :

Table 2. Results of the first regression

\begin{tabular}{ccccc}
\hline Variable & Coefficient & $\begin{array}{c}\text { Std. } \\
\text { Error }\end{array}$ & $\begin{array}{c}\text { t-Statisti } \\
\text { c }\end{array}$ & Prob. \\
\hline $\mathrm{C}$ & 6.017843 & 1.9031 & 3.1621 & 0.008 \\
$\ln \mathrm{F}$ & 1.116093 & 0.3073 & 3.6315 & 0.003 \\
\hline $\mathrm{R}^{2}$ & 0.523578 & AIC & 1.053 \\
$\mathrm{~A}^{2} \mathrm{R}^{2}$ & 0.483876 & SC & 1.144 \\
F-statistic & 13.18774 & Prob(F-statistic) & 0.000 \\
\hline
\end{tabular}

As shown in Table 2, The coefficient of $F$ is positive, indicating that $\mathrm{F}$ has a positive effect on $\mathrm{Y}$. The equation passed F-test and the variable passed t-test, but the $\mathrm{R}^{2}$ was only $52 \%$.

After replacing the explanatory variables, the regression analysis was made for $\ln \mathrm{Y}=\mathrm{C}+\alpha \ln \mathrm{J}+\mu$ :

Table 3. Results of the second regression

\begin{tabular}{ccccc}
\hline Variable & Coefficient & $\begin{array}{c}\text { Std. } \\
\text { Error }\end{array}$ & $\begin{array}{c}\text { t-Statist } \\
\text { ic }\end{array}$ & Prob. \\
\hline $\mathrm{C}$ & 6.559646 & 0.6034 & 10.869 & 0.000 \\
$\ln \mathrm{J}$ & 0.788093 & 0.0745 & 10.568 & 0.000 \\
\hline $\mathrm{R}^{2}$ & 0.902986 & \multicolumn{2}{c}{ AIC } & -0.538 \\
A-R $^{2}$ & 0.894902 & \multicolumn{2}{c}{ SC } & -0.447 \\
F-statistic & 111.6939 & Prob(F-statistic) & 0.000 \\
\hline
\end{tabular}

As shown in Table 3, The coefficient of $F$ is positive, indicating that $\mathrm{J}$ has a positive effect on $\mathrm{Y}$. The equation passed F-test and the variable passed t-test. The $\mathrm{R}^{2}$ reached $90 \%$. Compared with the previous results, the equation fits well.

In order to analyze the two explanatory variables at the same time, regression analysis was made for $\ln \mathrm{Y}=\mathrm{C}$ $+\alpha \ln F+\beta \ln J+\mu$ :

Table 4. Results of the third regression

\begin{tabular}{ccccc}
\hline Variable & Coefficient & $\begin{array}{c}\text { Std. } \\
\text { Error }\end{array}$ & $\begin{array}{c}\text { t-Statis } \\
\text { tic }\end{array}$ & Prob. \\
\hline $\mathrm{C}$ & 5.027478 & 0.6426 & 7.823 & 0.000 \\
$\ln \mathrm{F}$ & 0.413639 & 0.1249 & 3.311 & 0.007 \\
$\ln \mathrm{J}$ & 0.661011 & 0.0671 & 9.842 & 0.000 \\
\hline $\mathrm{R}^{2}$ & 0.951422 & \multicolumn{2}{c}{ AIC } & -1.087 \\
A-R $^{2}$ & 0.94259 & \multicolumn{2}{c}{ SC } & -0.951 \\
F-statistic & 107.7198 & Prob(F-statistic) & 0.000 \\
\hline
\end{tabular}

As shown in Table 4, the coefficients of $\mathrm{F}$ and $\mathrm{J}$ are both positive, indicating that $f$ and $j$ have a positive effect on $y$ at the same time. This result is consistent with the theoretical expectation, where the coefficient of $\mathrm{J}$ is greater than that of F. The equation passed F-test and the variable passed t-test. The $\mathrm{R}^{2}$ reached $95 \%$. Compared with the single explanatory variable, this equation fits better.

\section{Conclusion and Suggestion}

In the theoretical system of green GDP, there should be a positive correlation between investment in environment and green GDP. What is the relationship between increased investment in the environment and GDP in the current GDP system? The empirical study of this paper draws the following conclusions:

(1) Based on the empirical model, green investment has a positive impact on China's economic growth in recent years. Among them, the investment in the treatment of three wastes responds to the idea of energy conservation and emission reduction in circular economy, which is the most direct investment in pollution control; the investment in urban environmental infrastructure construction provides support for social environmental governance from another aspect.

(2) The results of the econometric model show that if other conditions remain unchanged, the GDP will increase by $0.41 \%$ for every $1 \%$ increase in investment in the treatment of three wastes; and the GDP will increase by $0.41 \%$ for every $1 \%$ increase in investment in urban environmental infrastructure construction.

(3) From the above analysis, it can be seen that the elastic sum of the investment in the treatment of three wastes and the investment in urban environmental infrastructure construction can reach more than 0.9 , which shows that the investment in environmental protection plays a significant role in promoting economic growth. Among them, the investment elasticity of urban environmental infrastructure construction is slightly higher, which shows that at the current stage, we should pay more attention to the prevention of pollution while paying attention to pollution control.

According to the above conclusions, this paper puts forward the following suggestions:

(1) Continue to increase green investment based on environmental governance after China's economy enters the new normal. In the long run, the improvement of environmental quality will improve the health level of workers, and environmental protection measures can also promote technological progress, which is mainly reflected in improving the utilization rate of resources. Therefore, in the future, it is still necessary to continue to strengthen the control of environmental pollution and constantly improve the efficiency of environmental pollution control in order to completely reverse the severe situation of environmental degradation.

From the above data, it can be seen that there is a positive correlation between environmental governance investment and economic growth. Theoretically, it has reached the rising stage of U-shaped curve, that is, environmental governance investment will continue to maintain the promotion of economic growth over time.

(2) The government should give full play to the function of using fiscal revenue to promote economic growth, and reasonably allocate the investment direction 
of governance environment. At the same time, the government should make clear its responsibility in environmental protection, give full play to the role of government environmental responsibility in restricting and supervising enterprises, build a strict environmental assessment standard for enterprise development and a comprehensive evaluation system for economic development, and increase punishment for enterprises that cause pollution. Guide enterprises to undertake certain social responsibilities and establish a positive image.

(3) Give full play to the public participation mechanism. It is very important to enhance the environmental awareness and enthusiasm of residents and enterprises to improve the environment. Therefore, it is necessary to publicize and explain the importance of environmental protection, and build a public environmental protection supervision platform, so that everyone can participate in the environmental pollution control.

\section{References}

1. Grossman, G.M., Krueger A.B., Environmental impacts of a North American Free Trade Agreement. NBER, Working paper 3914. (1991)

2. Eyraud L, Clements B, Wane A. Green Investment: Trends and Determinants. Energy Policy, 60(6): 852-865. (2013).

3. Starr M A. Socially responsible investment and pro - social change. Journal of Economic Issues, 42(1): 51-73. (2016).

4. Meng Yao. Green investment based on the protection of resources and environment and its development. Research on Financial and Economic Issues. 05(2007): 64-69. (2007).

5. Ren Guangqian, Cao Fan, et al. Investment in urban environmental infrastructure construction in China. Anhui Agricultural Science Bulletin. 21(17):78-79. (2015). 